九州大学学術情報リポジトリ

Kyushu University Institutional Repository

\title{
Desiccant Air-Conditioning System for Storage of Fruits and Vegetables: Pakistan Preview
}

Mahmood, Muhammad H.

Interdisciplinary Graduate School of Engineering Sciences, Kyushu University I International Institute for Carbon-Neutral Energy Research (WPI-I^2CNER)

Sultan, Muhammad

Department of Agricultural Engineering, Faculty of Agricultural Sciences \& Technology, Bahauddin Zakariya University | International Institute for Carbon-Neutral Energy Research (WPI-I^2CNER)

Miyazaki, Takahiko

Faculty of Engineering Sciences, Kyushu University | International Institute for CarbonNeutral Energy Research (WPI-I^2CNER)

Koyama, Shigeru

Faculty of Engineering Sciences, Kyushu University | International Institute for CarbonNeutral Energy Research (WPI-I’2CNER)

https://doi.org/10.5109/1657381

出版情報: Evergreen. 3 (1)，pp.12-17，2016-03. Green Asia Education Center バージョン：

権利関係 : 


\title{
Desiccant Air-Conditioning System for Storage of Fruits and Vegetables: Pakistan Preview
}

\author{
Muhammad H. Mahmood ${ }^{1,4, *}$, Muhammad Sultan ${ }^{2,4}$, Takahiko Miyazaki ${ }^{3,4}$, \\ Shigeru Koyama ${ }^{3,4}$ \\ ${ }^{1}$ Interdisciplinary Graduate School of Engineering Sciences, Kyushu University, \\ Kasuga-koen 6-1, Kasuga-shi, Fukuoka 816-8580, Japan \\ ${ }^{2}$ Department of Agricultural Engineering, Faculty of Agricultural Sciences \& Technology, \\ Bahauddin Zakariya University, Bosan Road, Multan 60800, Pakistan \\ ${ }^{3}$ Faculty of Engineering Sciences, Kyushu University, Kasuga-koen 6-1, \\ Kasuga-shi, Fukuoka 816-8580, Japan \\ ${ }^{4}$ International Institute for Carbon-Neutral Energy Research (WPI-I ${ }^{2} \mathrm{CNER}$ ), \\ Kyushu University, 744 Motooka, Nishi-ku, Fukuoka 819-0395, Japan \\ *Author to whom correspondence should be addressed, \\ *Email:mahmood@phase.cm.kyushu-u.ac.jp \\ (Received January 10, 2016; accepted February 24, 2016).
}

\begin{abstract}
In the present study the desiccant air-conditioning system has been investigated for the on-farm storage of fruits and vegetables in Pakistan. In this regard, ideal storage zone for the studied agricultural products is established in order to ascertain the system applicability. The dehumidification performance of the silica-gel based desiccant wheel has been analysed with low regeneration temperature $\left(50^{\circ} \mathrm{C}\right)$ by using the model of Beccali et. al. Three environmental conditions (A: highly humid, B: moderately humid \& C: less humid) are considered for the analysis of desiccant air-conditioning system. The latent and sensible loads of air-conditioning are achieved by the silica-gel desiccant wheel dehumidification and Maisotsenko cycle evaporative cooling respectively. The results of the study envisaged that desiccant wheel performs higher dehumidification in climatic condition ' $A$ ' due to higher ambient air relative humidity as compared to the other climatic conditions. However, higher heat energy is required for its regeneration in the climatic condition ' $\mathrm{A}$ '. This study concluded that the desiccant air-conditioning system can be efficiently used for on-farm storage of fruits and vegetables in Pakistan. Also, the renewable energy sources of the country like solar energy and bio-gas can be potentially harvested for the regeneration of desiccant wheel. The study further proposes the use of hybrid desiccant air-conditioning system where standalone DAC system cannot achieve the sensible load.
\end{abstract}

Keywords: desiccant, air-conditioning, agriculture, storage, Pakistan

\section{Introduction}

\subsection{Background of the storage}

The fruits and vegetables after harvesting act like living organisms and perform respiration, transpiration and ripening processes. Such agricultural products (fruits and vegetables) contain high moisture contents $(60-95 \%)^{1,2)}$ and may start spoiling within short time after the harvest which gives rise to the postharvest losses (PHL). The PHL are the losses of quality and quantity of the agricultural products throughout the postharvest chain. These losses may occur at any stage throughout the postharvest chain ${ }^{3}$. The main factors responsible for postharvest losses are mechanical damage, biological degradation, physiological deterioration, and attack of insects \& pests.
The reproduced schematic ${ }^{1)}$ which highlighted the effects of postharvest factors on the quality of the agricultural products is shown in Fig. 1. However, the postharvest quality (color, firmness, shape, weight) can be maintained to the greater extent by minimizing the PHL. The PHL can be minimized by cooling and storing the agricultural products at the farm right after their harvest that ultimately will increase their shelf/storage life. In this context, it has been reported that the storage/shelf life of the products can be enhanced by avoiding the postharvest cooling delays such as the shelf life of lettuce can be extended to 12 days by keeping it under optimal environmental conditions within one hour after the harvest ${ }^{4}$. Contrary, it has also been reported in the literature that the cooling delay of 3 hours at $37^{\circ} \mathrm{C}$ or 6 hours at $24^{\circ} \mathrm{C}$ after harvesting lowers 
the marketable quality and weight of the Japanese eggplants ${ }^{5)}$. Likewise, the cooling delay of just 3 hours after the harvest reduces the shelf life of the broccoli because of floret openings which ultimately affect its visual appearance ${ }^{6)}$ and cooling delay of 48 hours at $20^{\circ} \mathrm{C}$ shortened the storability of European plum due to increased internal breakdown ${ }^{7}$.

Pakistan being an agricultural country produces 12 million tonnes fresh fruits and vegetables annually ${ }^{8)}$. However, a huge amount of these fruits and vegetables is lost due to postharvest losses (30-35\%). The reason behind the higher PHL is mainly the severe lack of storage facilities at farm level and sometimes even away from farm. This necessitates the importance of farm level cold storage structure potentially equipped with environmentally friendly renewable energy operated cooling technologies.

\section{Nomenclature}

AC
DAC
DW
PHL
IEC
RH
RA
PA
E
$\mathrm{m}$
X
T
h

air-conditioning

desiccant air-conditioning

desiccant wheel

postharvest losses

indirect evaporative cooler

relative humidity $[\%]$

regeneration air

process air

effectiveness

mass flow rate $[\mathrm{kg} / \mathrm{sec}]$

humidity ratio $[\mathrm{g} / \mathrm{kgDA}]$

dry bulb temperature $\left[{ }^{\circ} \mathrm{C}\right]$

enthalpy $[\mathrm{kJ} / \mathrm{kg}]$

\subsection{Motivation for DAC system}

The conventional vapor compression refrigeration and/or air-conditioning systems are being used for preservation/storage of agricultural products. The disadvantages of the conventional refrigeration system are well known in literature ${ }^{9)}$ like environmental degradation and high energy requirements etc. Besides from these disadvantages, the conventional refrigerators cannot be used for on-farm storage of many tropical fruits and vegetables such as banana, tomatoes, oranges,

mangoes, and other leafy vegetables because of chilling injury and discoloration ${ }^{10)}$.

On the other hand, the standalone evaporative coolers also cannot be used in tropical climatic conditions because of higher relative humidity. However, the desiccant air conditioning (DAC) system has ability to deal with sensible and latent load of air conditioning distinctly. This distinction of DAC system gives opportunity to use this system for storage of agricultural products efficiently because both temperature and relative humidity are important for their optimal storage. In this regard, the temperature is most important factor to maintain the quality of the products because the physiological and biological reactions in the products are directly dependant on it. While, the relative humidity is also crucial in controlling the loss of moisture contents from the products in order to keep them in good physical and biological appearance $^{11)}$. A reproduced schematic of typical postharvest chain ${ }^{1,12}$ indicated the importance of storage throughout the postharvest chain is shown in Fig. 2.

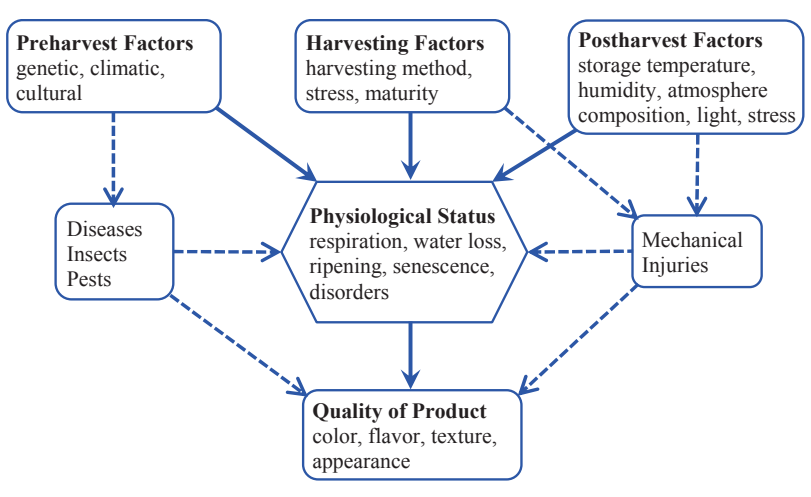

Fig. 1 Major factors affecting the product quality, reproduced from ref. Mishra et. $\mathrm{al}^{1)}$.

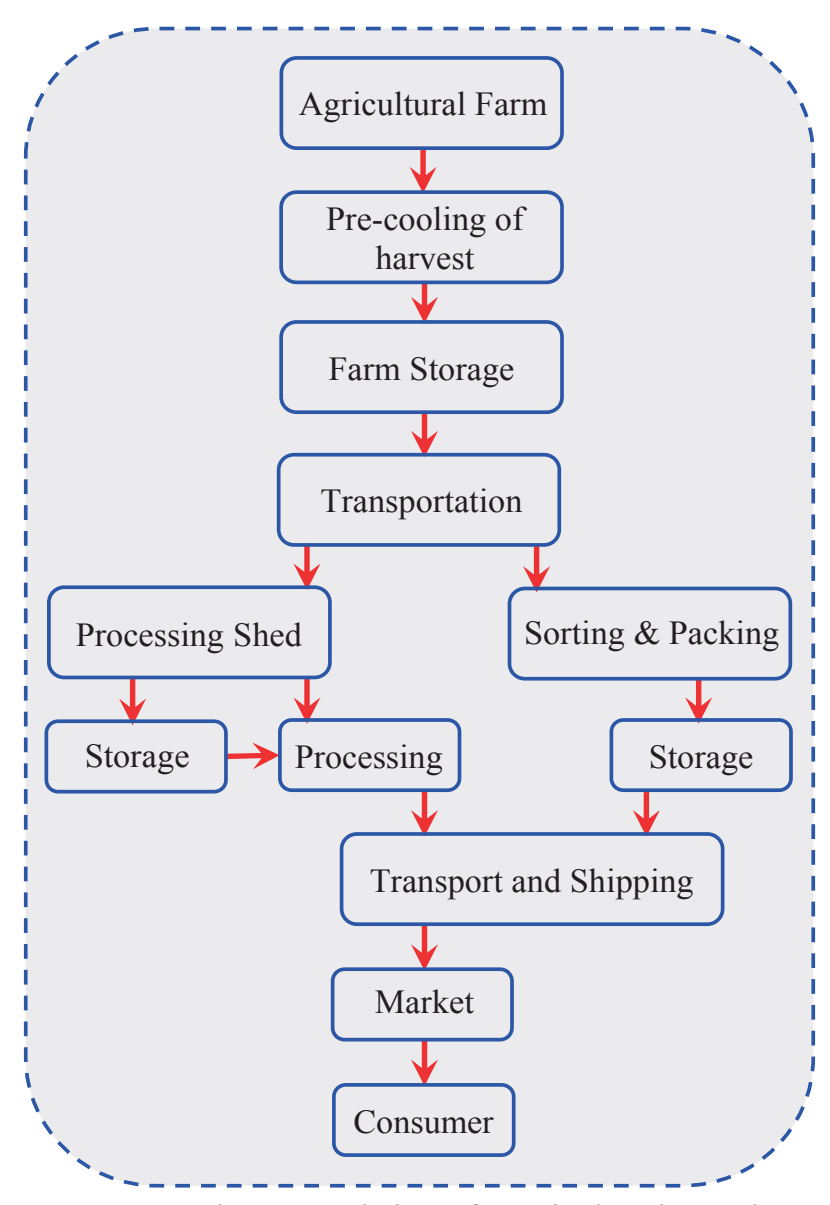

Fig. 2 Postharvest chain of agricultural products, reproduced from ref. Mishra et. al and Kader et. $\mathrm{al}^{1,12)}$. 
In short, shelf/storage life of agricultural products can be increased by avoiding the cooling delays after their harvest. Therefore, a particular DAC system is proposed in this study for on-farm storage of agricultural products in order to retard the physiological, biological and chemical changes in them by providing controlled temperature and relative humidity conditions.

In the purview of discussions made in sub sec. 1.1 and 1.2 , the objective of this study is to find the applicability of DAC system for on-farm storage of agricultural products (fruits and vegetables) under climatic conditions of Pakistan. The Fig. 3 elaborates the methodology adopted in this study to achieve the said objective and subsequent advantages. Therefore, firstly, the ideal zone for storage of tomatoes, sweet-potatoes, watermelons and pears is established for their safe storage life (details in sub sec. 2.1). Secondly, the silica gel DW dehumidification analysis is performed under low regeneration temperature using the model of Beccali et al. The low regeneration temperature is selected in order to harness the potential of renewable energy resources (solar energy and biogas) of the country for the purpose. (The detail about these renewable sources is discussed in sub sec 2.3) Finally, a particular DAC system is proposed to achieve the latent and sensible load to meet the developed storage zone conditions (temperature and relative humidity).

Table 1 climatic condition for DAC system analysis of proposed DAC system

\begin{tabular}{lcc}
\hline $\begin{array}{l}\text { Climatic } \\
\text { conditions }\end{array}$ & $\begin{array}{c}\text { Temperature } \\
{\left[{ }^{\circ} \mathrm{C}\right]}\end{array}$ & $\begin{array}{c}\text { Relative } \\
\text { humidity }[\%]\end{array}$ \\
\hline $\begin{array}{l}\text { A } \\
\text { (highly humid) }\end{array}$ & 23 & 90 \\
$\begin{array}{l}\text { B } \\
\text { (moderately }\end{array}$ & 28 & 70 \\
humid) \\
$\begin{array}{l}\text { (less humid) } \\
\text { (les }\end{array}$ & 33 & 50 \\
\hline
\end{tabular}

\section{Materials and Methods}

\subsection{Development of ideal storage zone}

The ideal temperature and relative humidity zone for preservation of tomatoes (mature green), sweet potatoes, watermelons and pears (for ripening) is developed on psychometric chart as shown in Fig. 4. All these products belong to same compatible temperature and relative humidity group. However, watermelons and sweetpotatoes are recommended to place separately from tomatoes and pears due to ethylene sensitivity. The temperature and relative humidity for safe storage of tomatoes (mature green), sweet potatoes, watermelons and pears (for ripening) is $18-21^{\circ} \mathrm{C}$ and $85-90 \%$ (i.e. humidity ratio about $10.95-14.0 \mathrm{~g} / \mathrm{kgDA}$ ) respectively ${ }^{13}$. The approximate transit and storage life of tomatoes (mature green), sweet potatoes and watermelons in weeks is $1-3,16-28$ and $2-3$ respectively ${ }^{13)}$. Whereas, the
European and Asian pears lasts for 6-12 and 3-6 months respectively by keeping them under optimal temperature and relative humidity conditions ${ }^{9,13)}$.

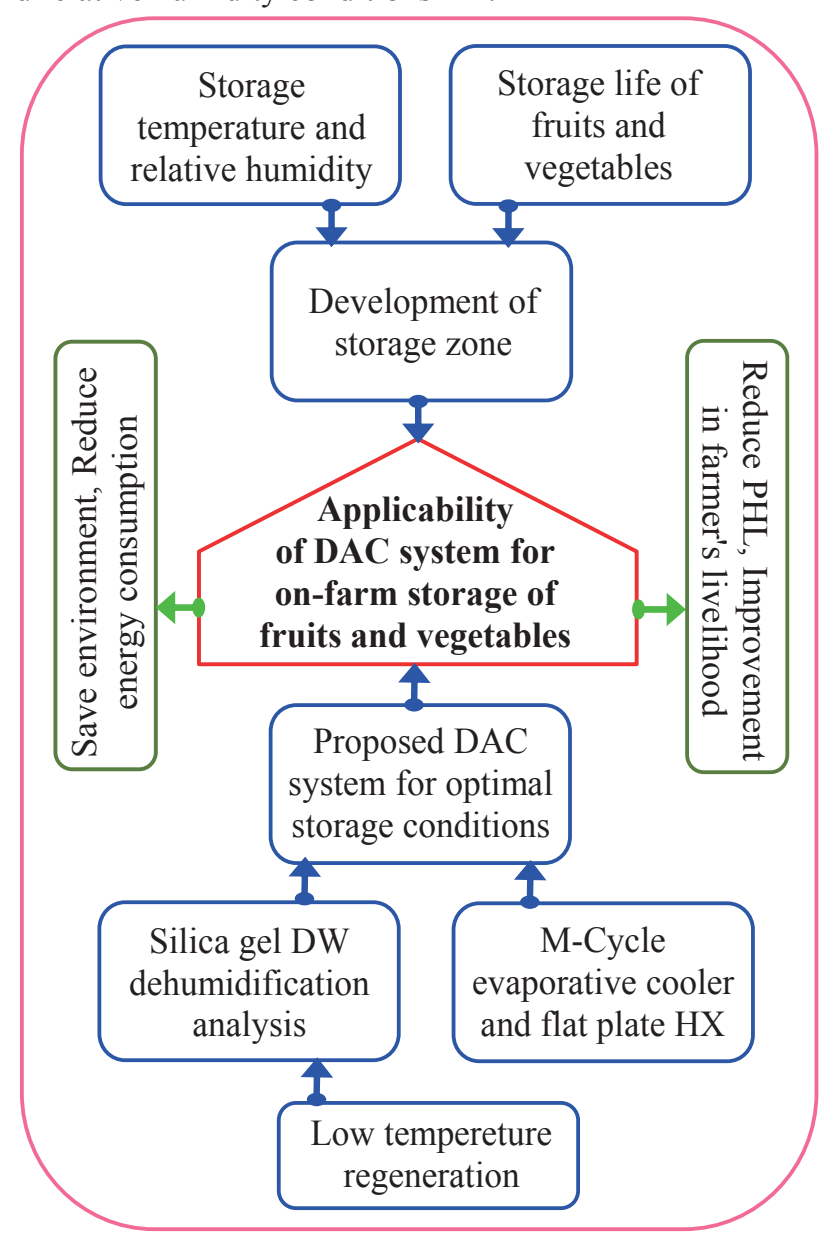

Fig. 3 Pictorial representation of the study objective and methodology

\subsection{Analysis of desiccant wheel performance}

The silica-gel desiccant wheel (DW) based DAC system is proposed in this study. The detail about proposed DAC system is discussed in forthcoming section 2.3. The performance analysis of silica gel based DW was carried out under different climatic conditions (Table 1) using the model of Beccali et al. ${ }^{14)}$.

It is important to mention that this model has already been tested/validated $\left(R^{2} \geq 0.9\right)$ against the wide range of field data for silica gel $\mathrm{DW}^{14,15)}$. Therefore, it can be used for analysis of DW performance in the present study. The following Eqs. 1-4 describe the model.

$$
\begin{aligned}
& h_{2}=0.1312 h_{7}+0.8688 h_{1} \\
& R H_{2}=0.9428 R H_{7}+0.0572 R H_{1} \\
& \frac{R H_{2} e^{0.053 T_{2}}-1.7976}{18671}=\frac{h_{2}-1.006 T_{2}}{2501-1.805 T_{2}} \\
& X_{2}=\begin{array}{c}
{\left[e^{0.053 T_{2}}\left(0.9428 R H_{7}+0.0572 R H_{1}\right)\right.} \\
-1.7976] / 18.671
\end{array}
\end{aligned}
$$


The above model equations have advantage of their simplicity and usage. This simple model can be used for the analysis of different kind of desiccant rotors (e.g. solid $\mathrm{LiCl}$ and silica gel) accurately under wide range of field data $^{14)}$.

The subscript in Eqs. (1-4) describes the different states of air of DAC cycle as shown in Fig. 4. The Eq. 1 was used to calculate the enthalpy at the outlet of desiccant wheel on the basis of enthalpy of process and regeneration air. Similarly, Eq. 2 was used to calculate the desiccant wheel outlet relative humidity in consideration of process and regeneration air relative humidity. However, the temperature of the dehumidified air was determined by performing iterations of Eq. 3. Finally, the humidity ratio of dehumidified air was calculated through Eq. 4 .

Therefore, the dehumidification of silica-gel desiccant wheel under given environmental conditions was performed by varying regeneration temperature from 50 to $80^{\circ} \mathrm{C}$ in order to check the efficacy of DAC system for agricultural product on-farm storage. The effect of regeneration temperature on the silica-gel desiccant wheel dehumidification is shown in Fig. 6. The low regeneration temperature $\left(50^{\circ} \mathrm{C}\right)$ was employed to simulate the use of low grade waste heat, solar energy and bio-gas for the cyclic operation of the system. The ideal DAC cycle is shown in Fig. 4.

\subsection{Proposed DAC system}

A typical desiccant wheel based DAC system shown in Fig. 5 is proposed for the on-farm storage of fruits and vegetables particularly for tomatoes, sweet-potatoes, watermelons and pears. In the proposed system, the dehumidification performance of silica gel desiccant wheel was analysed by the above mentioned model equations (Eq. 1-4) under three representative climatic conditions (A, B, C) of the Pakistan with low regeneration temperature $\left(50^{\circ} \mathrm{C}\right)$. The representative values of temperature and relative humidity of the climatic condition (A, B, C) are given in Table 1. The rest of system analysis was performed by the basic governing equations (Eqs. 5-8).

$$
\begin{aligned}
& T_{3}=T_{2}-\varepsilon_{H X}\left(T_{2}-T_{5}\right) \\
& T_{4}=T_{3}-\varepsilon_{M_{-} \text {Cycle }}\left(T_{3}-T_{1 w b}\right) \\
& T_{6}=T_{5}+\left(\frac{T_{2}-T_{3}}{m_{R A} / m_{P A}}\right)
\end{aligned}
$$

Heat input $=m_{R A} C_{p}\left(T_{7}-T_{6}\right)$

In this study flat plate heat exchanger with wet bulb effectiveness of 0.9 is used to recover the heat of adsorption. The Eq. 5 is used to calculate the process air temperature after the heat exchanger. It is important to mention that the Maisotsenko cycle evaporative cooler (effectiveness 0.6) is used to provide the conditioned supply air for the storage of agricultural products. Therefore, final supply temperature air was calculated by Eq. 6.

The heat input to the DW for its regeneration is calculated using Eq. 8. The regeneration temperature $\left(T_{7}\right)$ was varied from $50-80^{\circ} \mathrm{C}$ to calculate the varying heat input as shown in Fig. 5. Whereas, the mass flow rates of regeneration and process air are assumed as $1 \mathrm{~kg} / \mathrm{sec}$. The specific heat capacity of air is taken as $1.006 \mathrm{~kJ} / \mathrm{kg} \mathrm{K}$.

Table 2 Potential livestock sector strength of Pakistan for bio-gas generation

\begin{tabular}{lc}
\hline Species & No. (million) \\
\hline Buffaloes & 30.9 \\
Cattle & 34.3 \\
Goats & 59.9 \\
Sheep & 27.8 \\
Camel & 1.0 \\
Equines & 4.5 \\
\hline
\end{tabular}

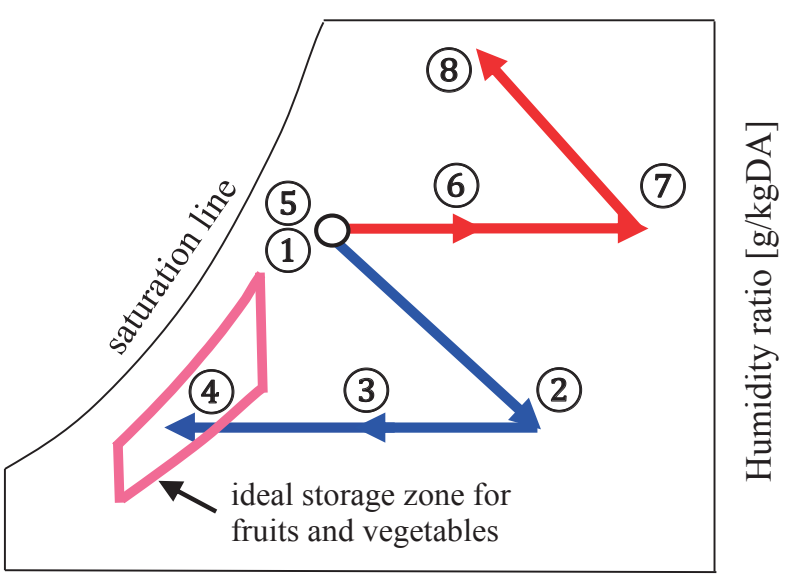

Dry bulb temperature $\left[{ }^{\circ} \mathrm{C}\right]$

Fig. 4 The ideal storage zone and DAC cycle

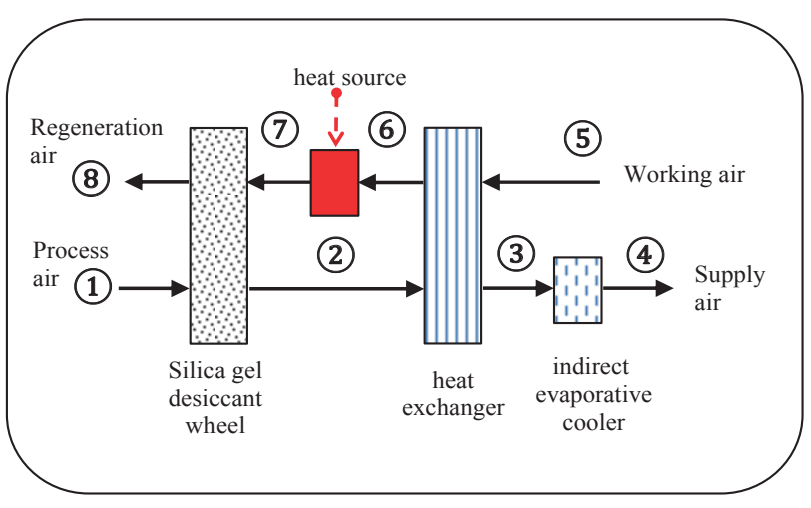

Fig. 5 The schematic of proposed DAC system 
As far regeneration of the desiccant wheel is concerned, Pakistan has huge potential of renewable energy sources like solar energy and bio-gas. In case of solar energy, the provinces (Baluchistan, Sindh and Punjab) of the country have abundant solar energy potential ${ }^{16)}$. The recorded daily sunshine hours are about 7-8 that means $2300-2700$ hours annually ${ }^{17)}$. The daily average global insolation is about $5-7 \mathrm{kWh} / \mathrm{m}^{2} /$ day with persistence factor of 85 percent. Such insolation is available on $95 \%$ areas of the country and has potential of solar energy about 18-25 $\mathrm{MJ} / \mathrm{m}^{2} /$ day $^{18)}$. A recent research reported that Pakistan due to its geographical location and environmental conditions has solar energy potential of about $2900 \mathrm{GWh}^{17)}$. On the other hand, the sources of bio-gas generation include livestock, bagasse and agriculture. Pakistan is rich in all these sources. The livestock sector strength as per Pakistan Economic Survey (2009-10) is shown in Table 2. The poultry waste also has huge potential for bio-gas generation as poultry head count is about 530 million $^{19)}$. The livestock and poultry sector are expanding and their growth rate was $2.88 \%$ in 2013-2014. As per estimates about 16.3 million $\mathrm{m}^{3}$ biogas can be produced daily by $50 \%$ feces of farm cattle \& buffaloes only ${ }^{20)}$. The one cubic meter of biogas can generate 1.5 to $2.5 \mathrm{kWh}$ of electricity and 2.5 to $4.0 \mathrm{kWh}$ of thermal energy depending upon the methane percentage ${ }^{14)}$. The bagasse production from country's sugar mills is also high as 5654 million tonnes per hour. Such amount of bagasse can produce energy about $1304 \mathrm{MW} / \mathrm{h}$; however, the current energy production is $478 \mathrm{MW} / \mathrm{h}$ only ${ }^{17)}$. Therefore, in purview of above discussion, the solar and bio-gas energy resources of the country have potential to be utilized for the purpose.

\section{Results and Discussion}

The proposed DAC system was analyzed for given environmental conditions. According to environmental condition ' $A$ ' the inlet air at relative humidity $90 \%$ and temperature $23^{\circ} \mathrm{C}$ passes through the desiccant wheel. The desiccant wheel dehumidifies the air to $11 \mathrm{~g} / \mathrm{kgDA}$ by which the air temperature increases about $40.3^{\circ} \mathrm{C}$ due to heat of adsorption under regeneration temperature of $50^{\circ} \mathrm{C}$. The dehumidified air is then entered to the heat exchanger for sensible cooling. Finally, the air is passed through MCycle evaporative cooler to supply the sensibly cooled conditioned supply air to the agricultural products. The system operates in similar fashion for other climatic conditions (B, C). Therefore, only one DAC cycle is represented in Fig. 4 to avoid the misunderstanding.

The results of this study further envisaged that the desiccant dehumidification capacity increases with increasing regeneration temperature. It is evident from the Fig. 6 that the comparative dehumidification trend under climatic conditions ' $\mathrm{A}$ ' and ' $\mathrm{B}$ ' decreases with increasing regeneration temperature. This leads towards the promising use of DAC system with low regeneration temperature under such climatic conditions. Also, the desiccant wheel under climatic condition ' $A$ ' performs higher dehumidification than other climatic conditions. It is because of higher relative humidity of process air in case of climatic condition ' $\mathrm{A}$ '. On the other hand, higher heat energy is required to regenerate the desiccant wheel under climatic condition ' $A$ ' because of higher dehumidification than the other studied conditions as shown in Fig. 7. However, it is important to mention that DAC system does not achieve sensible load under all considered climatic condition. Thus in such cases hybrid DAC system is recommended to achieve the sensible load.

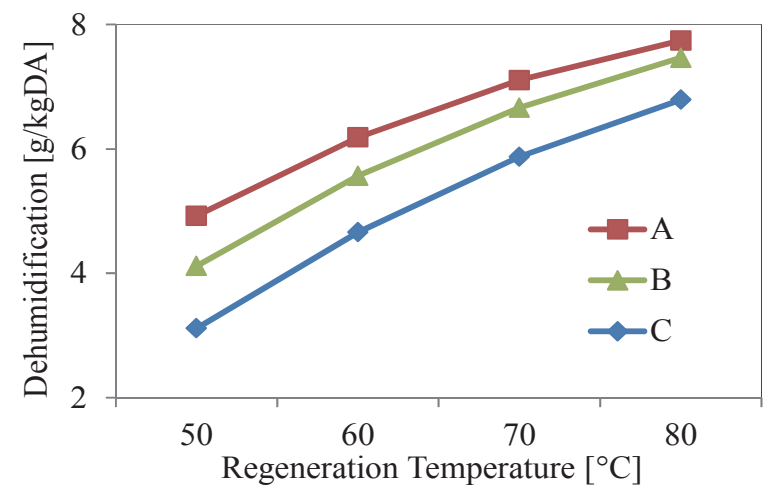

Fig. 6 Effect of regeneration temperature on desiccant wheel dehumidification

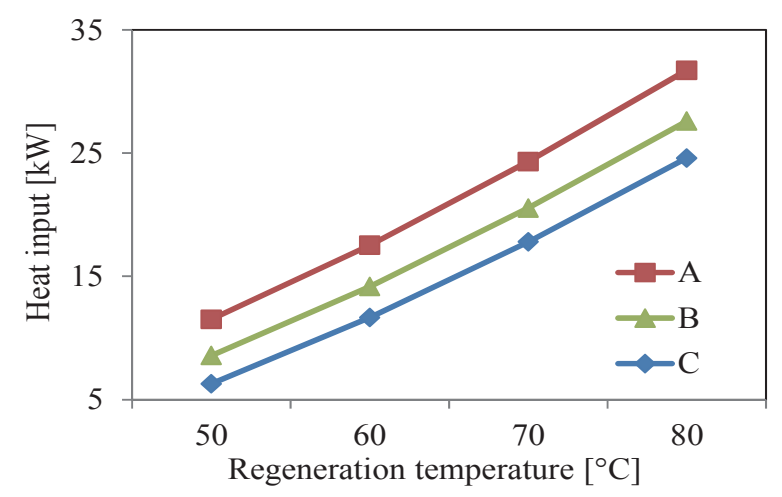

Fig. 7 Energy required for regeneration of desiccant wheel under different climatic conditions

\section{Conclusion}

In the present study the applicability of DAC system for the storage of agricultural products in Pakistan has been studied. Three climatic conditions (i.e. highly humid, moderately humid \& less humid) and variable regeneration temperature $\left(50-80^{\circ} \mathrm{C}\right)$ were considered for the system analysis. The silica-gel DW dehumidified the process air to the humidity ratio of $11-12.70 \mathrm{~g} / \mathrm{kgDA}$ under all the climatic conditions $(\mathrm{A}, \mathrm{B}, \mathrm{C})$ at regeneration temperature of $50^{\circ} \mathrm{C}$. This humidity ratio (11-12.70 $\mathrm{g} / \mathrm{kgDA}$ ) of the dehumidified air is well within the required humidity ratio $(10.95-14.0 \mathrm{~g} / \mathrm{kgDA})$ of the storage zone. Though, the increase in regeneration temperature $\left(60-80^{\circ} \mathrm{C}\right)$ results in higher dehumidification but such lower value of humidity ratio is not needed in this study becuase it crosses the lower limit of required 
humidity ratio (10.95 $\mathrm{g} / \mathrm{kgDA})$ of the storage zone. Therefore, the dehumidfied air at lower regeneration temperature $\left(50^{\circ} \mathrm{C}\right)$ is then pass through the flat plate heat exchanger to recover the heat of adsoption. Subsequently, the Maisotsenko cycle evaporative cooler (IEC) was employed to achieve the sensible load of the airconditioing in order to supply conditioned air required for safe storage of agricultural products. This envisaged that system can be potentially used with low regeneration temerature. However, in some cases the Maisotsenko cycle evaporative cooler does not achieve the sensible load, therefore, hybrid DAC system is being proposed in that situation.

The study concludes that DAC system can achieve the thermal conditions (latent and sensible load) required for on-farm storage of fruits and vegetables in general. The study, in particular, unveiled the potential applicability of DAC system for storage of agricultural products in most of the climatic conditions of Pakistan, with great potential of renewable energy (solar energy, bio-gas) resources to be used for cyclic operation of the system.

\section{References}

1) V. K. Mishra and T. V. Gamage, in Handbook of food preservation. 2nd ed., CRC press, Taylor and Francis group, USA, p. 19, 20, 50 (2007).

2) A. A. Kader, Ethiop. J. Appl. Sci. Technol, 1, 1. (2013).

3) R. J. Hodges, J. C. Buzby and B. Bennett, J. Agri. Scie., 149, 37 (2011)

4) M. V. Agüero, G. E. Viacava, M. R. Moreira and S. I. Roura, Intl. J. of Vegetable Scie., 20, 59 (2014).

5) M. I. Cantwell and A. Thangaiah, Proc. XXVIII Intl. Horti. Congress - Intl. Symp. on postharvest tech. in global market, Acta Hort. (ISHS) 934, 77, Lisbon, Portugal (2012).

6) P. S. Brennan and R. L. Shewfelt, J. Food Quality, 12, 13 (1989).

7) M. Guerra and P. A Casquero, J. Scie. Food and Agri., 89, 1076 (2009).

8) M. Shahzad, A. Tahir, N. Jehan, and M. Luqman, Paki. J. Agric. Res., 28, 53 (2015).

9) M. Sultan, I.I. El-Sharkawy, T. Miyazaki, B.B. Saha and S. Koyama, Renew. Sustain. Ener. Revie., 46, 19 (2015).

10) K. V. Vala, F. Saiyed and D. C. Joshi, Trends in Postharvest Tech., 2, 22 (2014).

11) A. L. Basediya, D. V. K. Samuel and V. Beera, J. of Food Scie. Tech., 50, 429 (2013).
12) A. A. Kader and R. S. Rolle, The role of post-harvest management in assuring the quality and safety of horticultural produce, 152, FAO-UN, Rome (2004).

13) L. Kitinoja, A. A. Kader, Small-Scale Postharvest Handling Practices: A Manual for Horticultural Crops, $4^{\text {th }}$ ed. UC, Davis, USA (2002).

14) M. Beccali, F. Butera, R. Guanella and R. S. Adhikari, Intl. J. Energy Res., 27, 17 (2003)

15) M. Beccali, R. S. Adhikari, F. Butera, V. Franzitta, Intl. J. Energy Res., 28, 1043 (2004).

16) M. A. Chaudhry, R. Raza, S. A. Hayat, Renew. Sustain. Ener. Revie., 13, 1657 (2009)

17) S. Ahmed, A. Mahmood, A. Hasan, G. A. S. Sidhu, M. F. U. Butt, Renew. Sustain. Ener. Revie., 57, 216 (2016).

18) M. Sultan, K. Yoshida, I.I. El-Sharkawy, T. Miyazaki, B.B. Saha and S. Koyama, IMPRES, Japan (2013).

19) A. Raheem, M. Y. Hassan, R. Shakoor, Renew. Sustain. Ener. Revie., 59, 264 (2016).

20) S. S. Amjid, M. Q. Bilal, M. S. Nazir, A. Hussain, Renew. Sustain. Ener. Revie., 15, 2833 (2011). 